Research Article

\title{
Obtaining Silicon Oxide Nanoparticles Doped with Fluorine and Gold Particles by the Pulsed Plasma-Chemical Method
}

\author{
Galina Kholodnaya ${ }^{D},{ }^{1}$ Roman Sazonov ${ }^{1},{ }^{1}$ Denis Ponomarev ${ }^{(D)},{ }^{1}$ and Igor Zhirkov ${ }^{2}$ \\ ${ }^{1}$ Tomsk Polytechnic University, 2 a Lenin Avenue 634028, Tomsk, Russia \\ ${ }^{2}$ Linköpings Universitet, Department of Physics, Linkoping, Sweden
}

Correspondence should be addressed to Galina Kholodnaya; galina_holodnaya@mail.ru

Received 17 December 2018; Revised 30 January 2019; Accepted 7 February 2019; Published 7 March 2019

Academic Editor: Marco Rossi

Copyright (c) 2019 Galina Kholodnaya et al. This is an open access article distributed under the Creative Commons Attribution License, which permits unrestricted use, distribution, and reproduction in any medium, provided the original work is properly cited.

This paper presents a study on pulsed plasma-chemical synthesis of fluorine- and gold-doped silicon oxide nanopowder. The goldand fluorine-containing precursors were gold chloride $\left(\mathrm{AuCl}_{3}\right)$ and sulphur hexafluoride $\left(\mathrm{SF}_{6}\right)$. Pulsed plasma-chemical synthesis is realized on the laboratory stand, including a plasma-chemical reactor and TEA-500 electron accelerator. The parameters of the electron beam are as follows: $400-450 \mathrm{keV}$ electron energy, $60 \mathrm{~ns}$ half-amplitude pulse duration, up to $200 \mathrm{~J}$ pulse energy, and $5 \mathrm{~cm}$ beam diameter. We confirmed the composite structure of $\mathrm{Si}_{x} \mathrm{O}_{y} @ \mathrm{Au}$ by using transmission electron microscopy and energydispersive spectroscopy. We determined the chemical composition and morphology of synthesized $\mathrm{Si}_{x} \mathrm{O}_{y} @ \mathrm{Au}_{\mathrm{u}}$ and $\mathrm{Si}_{x} \mathrm{O}_{y} @ \mathrm{~F}$ nanocomposites. The material contained a $\mathrm{Si}_{x} \mathrm{O}_{y} @ \mathrm{Au}$ carrier with an average size of 50-150 nm and a shell of fine particles with an average size of $5-10 \mathrm{~nm}$.

\section{Introduction}

Silicon dioxide $\left(\mathrm{SiO}_{2}\right)$ nanopowder is widely used in various industries. It is used as a filler for polymeric paint and lacquer materials, improving the abrasion and durability of paints $[1,2] . \mathrm{SiO}_{2}$ is often used as a food additive with the intention of avoiding the clumping and caking of food $[3,4]$. It is also used in the manufacture of toothpastes and medicines $[5,6] . \mathrm{SiO}_{2}$ is one of the main components in the production of glass, abrasives, ceramics, and concrete $[7,8]$. Silicon dioxide is used in radio electronics, in particular, the production of microcircuits and fibre optic cables $[9,10]$. At present, the properties of nanocomposite structures, which are used to create materials with preassigned properties, are being actively studied in modern solid-state physics [11-14]. Production of a composite based on $\mathrm{SiO}_{2}$ with various chemical elements $(\mathrm{C}, \mathrm{Au}$, and $\mathrm{F})$ enables the improvement of the physical and chemical properties of the synthesized composite and expands its scope of use. Among such composites, $\mathrm{SiO}_{2} @ \mathrm{Au}$ and $\mathrm{SiO}_{2} @ \mathrm{~F}$ composites deserve special attention. Nanoparticles of noble metals attract much attention because of their unique properties and many applications: chemical analysis, medical diagnostics and treatments, sensors, bactericidal materials, surface-enhanced Raman spectroscopy (SERS), enhancement of the fluorescence of organic dyes, etc. [15-19]. To obtain the nanoscale composites of $\mathrm{SiO}_{2} @ \mathrm{Au}$ and $\mathrm{SiO}_{2} @ \mathrm{~F}$, the liquid-phase method, sol-gel method, classical chlorine process, and flame synthesis are used, among other methods [20-27].

In [21], a mesoporous $\mathrm{SiO}_{2} @ \mathrm{Au}$ composite with a specific surface area of $650 \mathrm{~m}^{2} / \mathrm{g}$ was obtained using the solgel method. The following silicon- and gold-containing precursors were used for the synthesis: tetraethoxysilane $\left(\mathrm{C}_{2} \mathrm{H}_{5} \mathrm{O}\right) 4 \mathrm{Si}$ of high purity $(99 \%)$ and sodium tetrachloroaurate $\left(\mathrm{AuCl}_{4} \mathrm{Na}\right)$. The obtained composite was stabilized by annealing in air at $600^{\circ} \mathrm{C}$. The composite would be useful as a standard for studying the optical and catalytic properties of particles of noble metals. The $\mathrm{SiO}_{2} @ \mathrm{Au}$ composite was synthesized in [22] using a combination of the sol-gel method and calcination processes. In studies of 
the physical and chemical properties of composites, it was found that the calcination temperature has an obvious effect on the morphology and structure of the sample. The catalytic activity of the $\mathrm{SiO}_{2} @ \mathrm{Au}$ nanocomposite was studied, and it was found that the synthesized $\mathrm{SiO}_{2} @ \mathrm{Au}$ composites possess high catalytic activity. In [23], the $\mathrm{SiO}_{2} @ \mathrm{Au}$ composite was synthesized by the sol-gel method. The synthesis process included four steps: (a) preparation of silicon dioxide; (b) grafting gold nanoparticles over a $\mathrm{SiO}_{2}$ shell; (c) priming of the silica-coated gold nanoparticles with 2 to $10 \mathrm{~nm}$ gold colloids; and finally (d) formation of the complete shell. The average size of the synthesized particles was $170 \mathrm{~nm}$ with a standard deviation of $18 \mathrm{~nm}$. The $\mathrm{SiO}_{2} @ \mathrm{Au}$ composite was obtained in [27] via the Stöber chemical method. The composite consisted of two particles of $\mathrm{SiO}_{2}$ and $\mathrm{Au}$. The average particle size for $\mathrm{SiO}_{2}$ was about $300 \mathrm{~nm}$ and $100 \mathrm{~nm}$ for Au. The $\mathrm{SiO}_{2} @ \mathrm{Au}$ nanocomposites possessed enhanced electrical and mechanical properties compared with silicon dioxide nanoparticles.

At this stage of research in the field of obtaining nanocomposites based on silicon dioxide doped with fluorine or gold particles, the possibility of organizing a pulsed plasma-chemical process for producing such nanomaterials has not been studied. This work is devoted to experimental research in this direction.

\section{Experimental}

The ultrafine silicon dioxide was synthesized using a TEA500 pulsed electron accelerator [28-32]. Silicon tetrachloride, hydrogen, and oxygen were used in the experiments. The reaction chamber was pumped out to a pressure of $\sim 7.6 \mathrm{~Pa}$ before introducing the mixture of gases. Figure 1 shows the experimental setup.

To obtain $\mathrm{Si}_{x} \mathrm{O}_{y} @ \mathrm{Au}$ nanocomposites, we used gold chloride $\left(\mathrm{AuCl}_{3}\right)$. The gold-containing precursor was obtained from jewellers' gold by dissolution followed by evaporation. The composition of jewellers' gold contains $58.5 \%$ gold, copper $33.5 \%$, and silver $8 \%$. The plasma-chemical reactor was preevacuated to 5 Torr, while $\mathrm{SiCl}_{4}, \mathrm{O}_{2}, \mathrm{H}_{2}$, and $\mathrm{AuCl}_{3}$ were simultaneously introduced; after that, the reactor was heated to $180^{\circ} \mathrm{C}$. As a result of heating, gold trichloride was decomposed into gold monochloride and molecular chlorine.

$$
\mathrm{AuCl}_{3} \longrightarrow \mathrm{AuCl}+2 \mathrm{Cl}_{2}
$$

Next, a pulsed electron beam was injected into the reactor, initiating reactions to obtain a nanosized silica powder as described in [30]. One of the by-products of plasmachemical synthesis is water vapour. The synthesis process had a chain character and proceeded with significant heat generation. Two factors, namely, elevated temperature and moisture, contributed to the decomposition of gold monochloride $(\mathrm{AuCl})$ into $\mathrm{Au}$ and $\mathrm{AuCl}_{3}$.

As a result, $\mathrm{Si}_{x} \mathrm{O}_{y} @ \mathrm{Au}$ nanopowder was produced (the mass of the obtained powder was about $1.2 \mathrm{~g}$ per one act of pulsed electron beam impact on the initial reagents).

To obtain the $\mathrm{Si}_{x} \mathrm{O}_{y} @ \mathrm{~F}$ composite, the following reagents were used: sulphur hexafluoride, silicon tetrachloride, hydrogen, and oxygen. The initial reagents were injected into the plasma-chemical reactor, followed by the injection of the

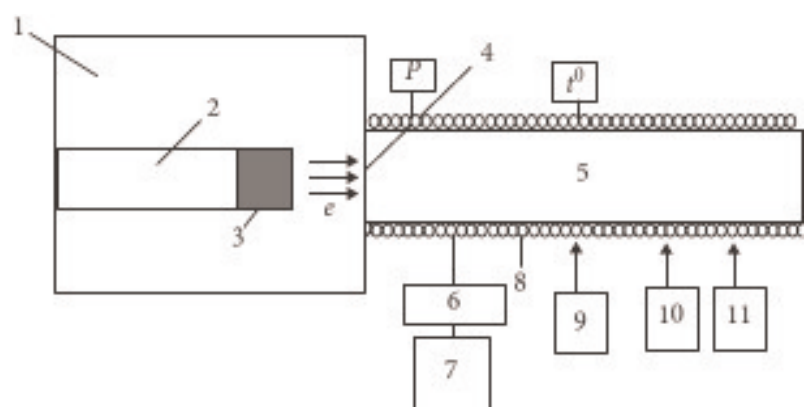

Figure 1: Scheme of experiment: diode chamber of the TEA-500 accelerator (1); cathode holder (2); cathode (graphite, $45 \mathrm{~mm}$ diameter) (3); anode grid (3 mm thick) (4); plasma-chemical reactor (PCR) (5); product collection system (6); high-pressure vacuum pump (7); PCR heating unit (8); oxygen cylinder (9); hydrogen cylinder (10); $\mathrm{SiCl}_{4}$ dispenser (11).

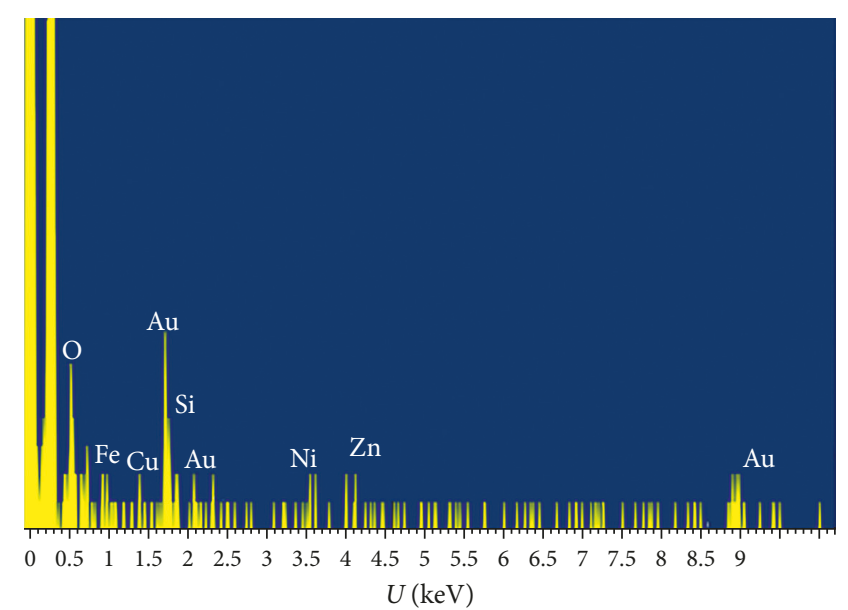

FIgURE 2: The X-ray fluorescence spectrum of the $\mathrm{Si}_{x} \mathrm{O}_{y} @ \mathrm{Au}$ composite nanomaterials.

electron beam. As a result of the action of a pulsed electron beam on a gas mixture $\left(\mathrm{SF}_{6}+\mathrm{SiCl}_{4}+\mathrm{H}_{2}+\mathrm{O}_{2}\right)$, several parallel chemical reactions were initiated. These reactions stimulated the interaction of chlorine and hydrogen, the oxidation of hydrogen, and the oxidation of sulphur hexafluoride with the formation of oxofluorides ( $\mathrm{OF}, \mathrm{OF}_{2}$, etc.), which participated in the synthesis of the final product of $\mathrm{Si}_{x} \mathrm{O}_{y} @ \mathrm{~F}$. Synthesized $\mathrm{Si}_{x} \mathrm{O}_{y} @ \mathrm{~F}$ powders were white. During the action of the pulsed electron beam, the mass of the obtained powder was about 0.8 g. Pulsed plasma-chemical synthesis of the $\mathrm{Si}_{x} \mathrm{O}_{y} @ \mathrm{Au}$ and $\mathrm{Si}_{x} \mathrm{O}_{y} @ \mathrm{~F}$ nanocomposites was implemented in one step; all reagents were mixed in advance, and the synthesis process was implemented in one pulse. Moreover, no additional technological operations were required such as hardening and drying.

\section{Results and Discussion}

The chemical composition of the $\mathrm{Si}_{x} \mathrm{O}_{y} @ A u$ nanocomposite, obtained using the pulsed plasma-chemical method, was determined using an Oxford Instruments ED2000 energydispersive X-ray fluorescence spectrometer. The X-ray fluorescence spectrum of the synthesized composite is shown in Figure 2. 


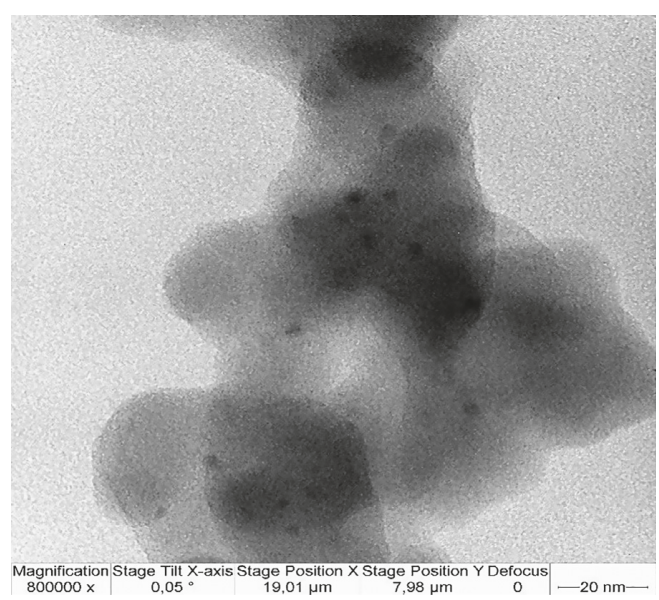

(a)

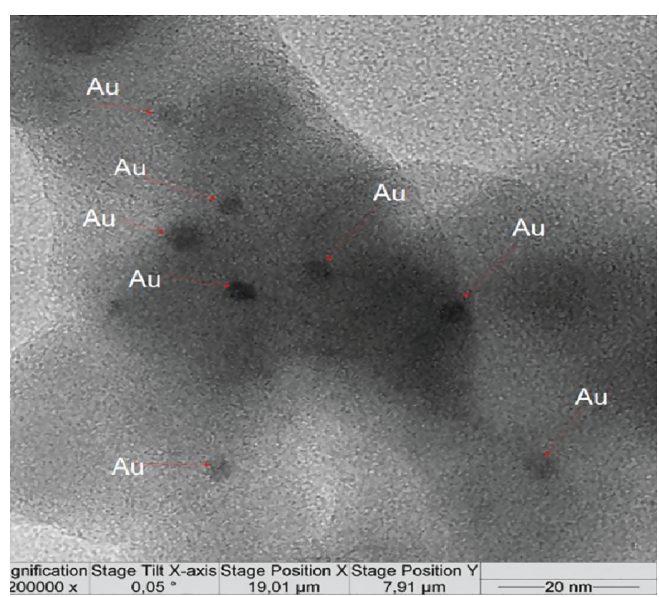

(c)

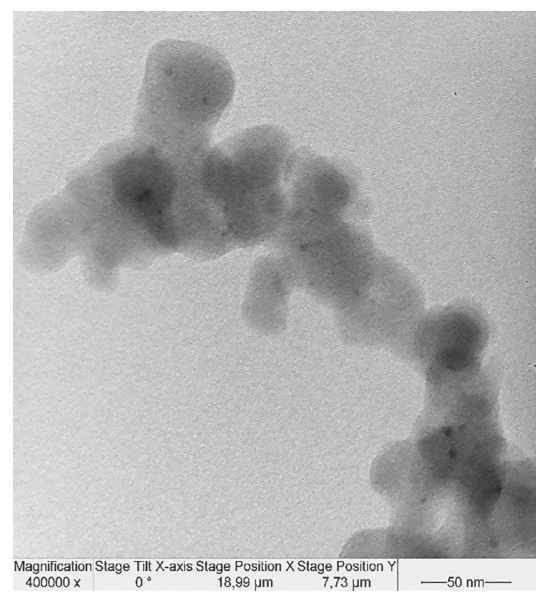

(b)

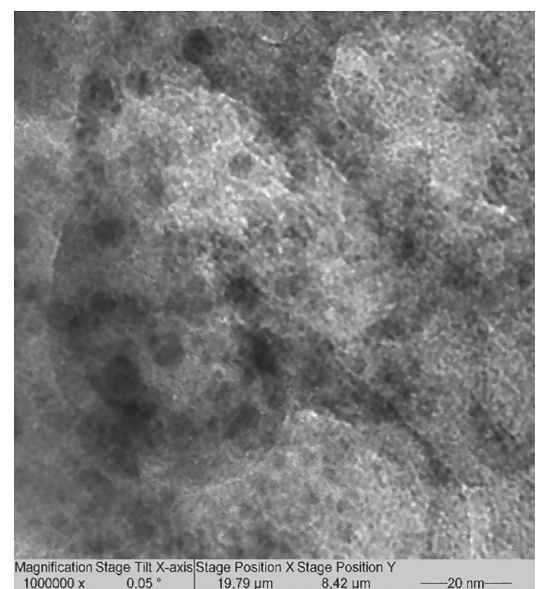

(d)

Figure 3: TEM images of the $\mathrm{Si}_{x} \mathrm{O}_{y} @ \mathrm{Au}$ composite.

As can be seen from Figure 2, in addition to gold, the material contains a significant amount of impurities of copper, zinc, and nickel, which is likely because gold of gem quality was used to create the initial gold-containing precursor. Moreover, the iron content was noticeable, which can be explained by the participation of the metal parts of the reactor in the synthesis process during heating.

The Brunauer-Emmett-Teller (BET) method was used to study the specific surface area for all synthesized $\mathrm{Si}_{x} \mathrm{O}_{y} @$ $\mathrm{Au}$ samples. The specific surface area for the synthesized $\mathrm{Si}_{x} \mathrm{O}_{y} @ \mathrm{Au}$ samples ranged from 140 to $220 \mathrm{~m}^{2} / \mathrm{g}$.

The morphology of the $\mathrm{Si}_{x} \mathrm{O}_{y} @ \mathrm{Au}$ nanocomposites was determined using a JEOL-II-100 (Jeol Ltd., Japan) transmission electron microscope. The morphology of the $\mathrm{Si}_{x} \mathrm{O}_{y} @$ $\mathrm{Au}$ nanocomposites is shown in Figure 3.

The TEM images show that the synthesized particles had an irregular shape evenly covered with fine particles (Figures 3(a) and 3(b)). Powder morphology is represented by globules consisting of spherical- or oval-shaped fused nanoparticles. Two regions are noticeable in the images: dark (Au particles) and light ( $\mathrm{Si}_{x} \mathrm{O}_{y}$ particles), which indicates that the composite particles consisted of two components. The morphology of the composite was characterized by clusters of particles amalgamated into a single structure. The morphology of small particles was rounded (Figure 3(c)). Small particles of gold are evenly distributed on the surface of large particles (Figure 3(d)). The average size of the small particles $(\mathrm{Au})$ ranged from 5 to $10 \mathrm{~nm}$, and the diameter of the $\mathrm{Si}_{x} \mathrm{O}_{y}$ particles ranged from 60 to $150 \mathrm{~nm}$. Figure 4 presents the histogram of the particle size distribution. Histograms were constructed with a sample of over 1000 particles.

The silicon oxide in the obtained nanocomposites was amorphous. The synthesized $\mathrm{SiO}_{2} @ \mathrm{Au}$ composites were studied using an energy-dispersive X-ray spectroscopy (EDX method). The relative content of oxygen and silicon in the $\mathrm{Si}_{x} \mathrm{O}_{y} @ \mathrm{Au}$ composite according to EDX-spectra was $26 \mathrm{wt} . \%$ and $57 \mathrm{wt} . \%$, respectively. Mass content of gold in the composite was $17 \%$.

Figure 5 shows micrographs of the synthesized $\mathrm{Si}_{x} \mathrm{O}_{y} @ \mathrm{~F}$ nanomaterial.

The nanomaterial had an amorphous structure, as evidenced by the absence of reflections on the microdiffractogram. The size of the $\mathrm{Si}_{x} \mathrm{O}_{y} @ \mathrm{~F}$ composite powders ranged from $20-45 \mathrm{~nm}$ (Figure 6).

Using the energy-dispersive X-ray spectroscopy (EDS) method, particles of the $\mathrm{Si}_{x} \mathrm{O}_{y} @ \mathrm{~F}$ nanocomposite were 


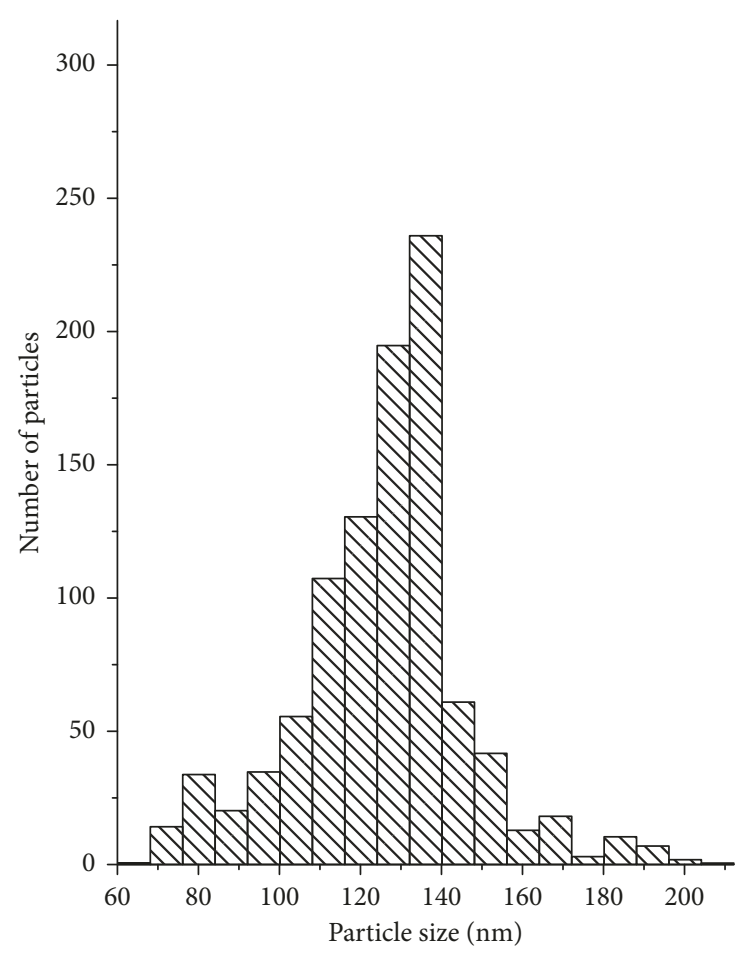

Figure 4: Histogram of the distribution of sizes.

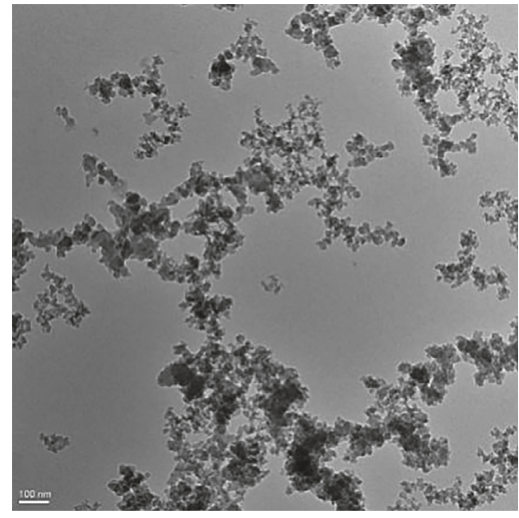

(a)

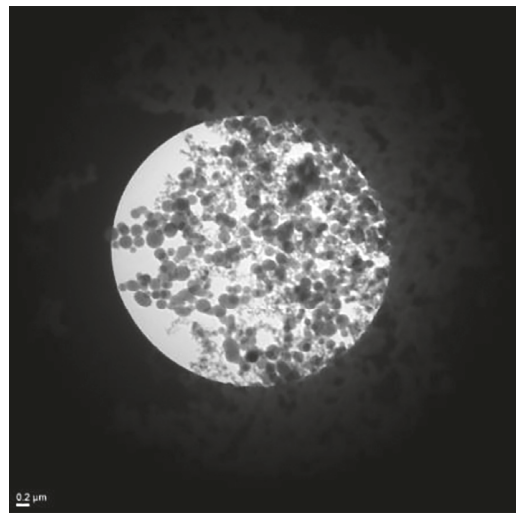

(b)

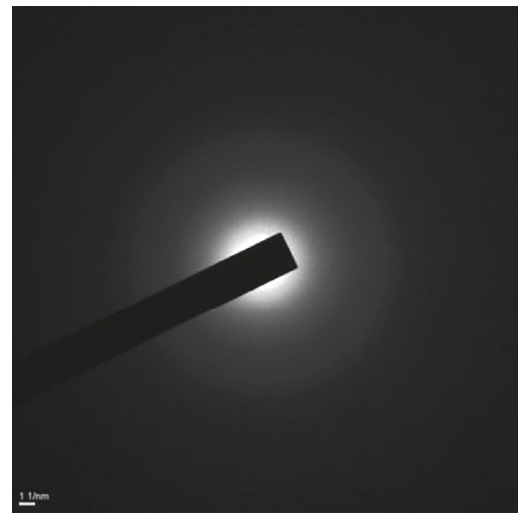

(c)

Figure 5: TEM image of the $\mathrm{Si}_{x} \mathrm{O}_{y} @ \mathrm{~F}$ nanocomposite and its microdiffractogram.

analysed to estimate the fluorine content in the synthesized samples. The spectrum was taken at 20 points. Fluorine was rather evenly distributed throughout the nanomaterial particles. The average content reached 48 at.\%, which indicates that fluorine is mainly located on the surface.

Figure 7 shows the characteristic infrared absorption spectra of the $\mathrm{Si}_{x} \mathrm{O}_{y} @ \mathrm{~F}$ composite powders in the range from 400 to $4000 \mathrm{~cm}^{-1}$ (Nicolet 5700, Thermo Fisher Scientific, USA). The studied powder was premixed with $\mathrm{KBr}$ and pressed into a tablet. The reflection spectrum of pure $\mathrm{KBr}$ was subtracted from the reflection spectrum of the mixture.

The IR absorption spectrum shows absorption bands typical for the $\mathrm{Si}_{x} \mathrm{O}_{y}$ material. The 1090 and $815 \mathrm{~cm}^{-1}$ peaks responsible for $\mathrm{Si}-\mathrm{O}-\mathrm{Si}$ bond fluctuation were typical for the samples under study. The $460 \mathrm{~cm}^{-1}$ peak is responsible for the bond oscillations in the $\mathrm{Si}-\mathrm{O}-\mathrm{Si}$ group. The band with a center of $\sim 940 \mathrm{~cm}^{-1}$ corresponds to the stretching vibrations of the internal $\mathrm{OH}$-bond of $\mathrm{SiOH}$. In addition, we recorded the bands at $1500-2000 \mathrm{~cm}^{-1}$ in the spectrum, which correspond to the $\mathrm{H}-\mathrm{O}-\mathrm{H}$ group. The stretching vibrations of hydroxyl groups and water molecules, $v_{\mathrm{OH}}$, form an intense band in the region of $3200-3600 \mathrm{~cm}^{-1}[33,34]$. This fact suggests that, in addition to physically adsorbed fluorine, the surface of the nanoparticles probably contains largely silanol groups $(\mathrm{SiOH})$, which adsorb water molecules [35]. Comparing the reflection spectra of the composite $\mathrm{Si}_{x} \mathrm{O}_{y} @ \mathrm{~F}$ and the $\mathrm{SiO}_{2}$ nanopowder obtained by the pulsed plasma-chemical method [36], an absolutely identical picture can be seen. Addition of sulphur hexafluoride to the initial mixture did not lead to the formation of chemical bonds that could be fixed. 


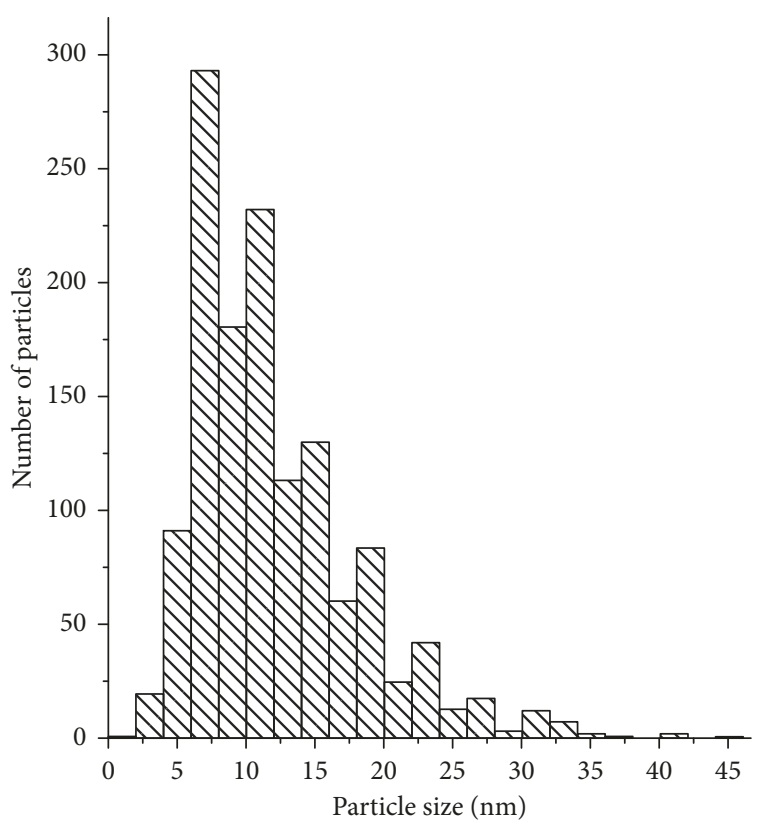

Figure 6: Histogram of the size distribution.

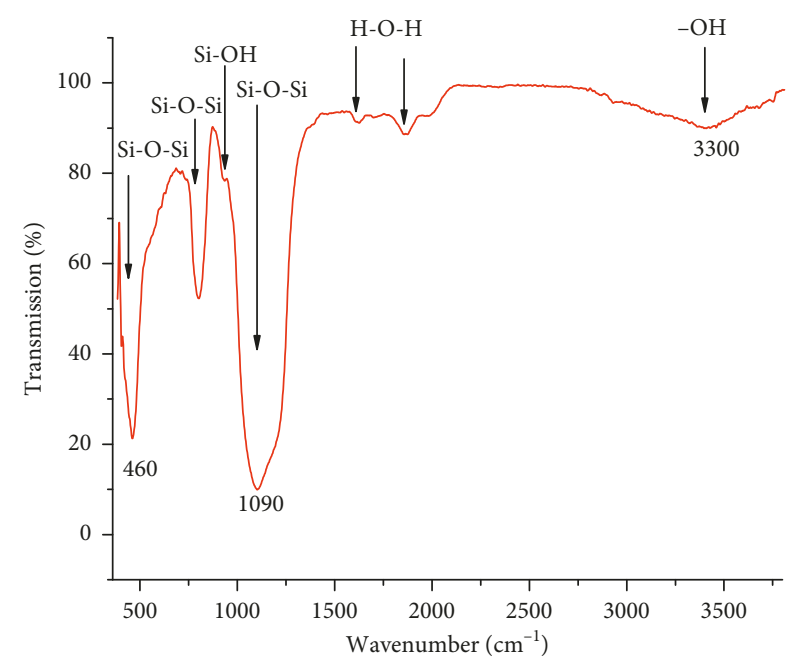

Figure 7: IR absorption spectrum of the $\mathrm{Si}_{x} \mathrm{O}_{y} @ \mathrm{~F}$-synthesized nanocomposites.

\section{Conclusion}

We have shown that it is possible to synthesize nanosized silicon dioxide doped with gold particles and fluorine by using a pulsed plasma-chemical process. The $\mathrm{Si}_{x} \mathrm{O}_{y} @ \mathrm{Au}$ and $\mathrm{Si}_{x} \mathrm{O}_{y} @ \mathrm{~F}$ composite powders, which consist of particles of irregular shape with a diameter of 20 to $100 \mathrm{~nm}$, were synthesized. Silicon oxide in the obtained nanocomposites was amorphous. In the TEM images of $\mathrm{Si}_{x} \mathrm{O}_{y} @ \mathrm{Au}$ nanocomposites, fine $\mathrm{Au}$ particles uniformly distributed on the surface of larger particles are visible.

Synthesized composites have a high potential for use as catalysts. The use of $\mathrm{Si}_{x} \mathrm{O}_{y} @ \mathrm{Au}$ as a filler for conductive inks is also possible. The $\mathrm{Si}_{x} \mathrm{O}_{y} @ \mathrm{~F}$-synthesized composites have a high potential as an additive for paints, as it is known from the literature that particles with a fluorine-containing surface have hydrophobic properties. In addition, the synthesized composite can be of interest to additive technologies. Due to the fluorine content in the surface layer of the nanoparticles, it is potentially possible to use the nanoparticles in order to reduce the temperature at which the $3 \mathrm{D}$ printing process takes place.

\section{Data Availability}

The data used to support the findings of this study are available from the corresponding author upon request.

\section{Conflicts of Interest}

The authors declare that they have no conflicts of interest.

\section{Acknowledgments}

This study was partially supported by the Russian Science Foundation (research project no. 17-73-10269).

\section{References}

[1] X. Wei, J. Yu, L. Ding, J. Hu, and W. Jiang, "Effect of oxide nanoparticles on the morphology and fluidity of phospholipid membranes and the role of hydrogen bonds," Journal of Environmental Sciences, vol. 57, pp. 221-230, 2017.

[2] S. Das, J. Manam, and S. K. Sharma, "Role of rhodamine-B dye encapsulated mesoporous $\mathrm{SiO}_{2}$ in color tuning of $\mathrm{SrAl}_{2} \mathrm{O}_{4}$ : $\mathrm{Eu}^{2+}, \mathrm{Dy}^{3+}$ composite long lasting phosphor," Journal of Materials Science: Materials in Electronics, vol. 27, no. 12, pp. 13217-13228, 2016.

[3] N. V. Zaytseva, M. A. Emlyanova, V. N. Vezdin et al., "Toxicological assessment of nanostructured silica," Acute Oral Toxicity, vol. 83, no. 2, pp. 42-49, 2014.

[4] R. Yusoff, L. T. H. Nguyen, P. Chiew, Z. M. Wang, and K. W. Ng, "Comparative differences in the behavior of $\mathrm{TiO}_{2}$ and $\mathrm{SiO}_{2}$ food additives in food ingredient solutions," Journal of Nanoparticle Research, vol. 20, no. 3, p. 76, 2018.

[5] H. Bouwmeester, M. van der Zande, and M. A. Jepson, "Effects of food-borne nanomaterials on gastrointestinal tissues and microbiota," Wiley Interdisciplinary Reviews: Nanomedicine and Nanobiotechnology, vol. 10, no. 1, pp. e1481-e1493, 2018.

[6] A. Tadayon, R. Jamshidi, and A. Esmaeili, "Delivery of tissue plasminogen activator and streptokinase magnetic nanoparticles to target vascular diseases," International Journal of Pharmaceutics, vol. 495, no. 1, pp. 428-438, 2015.

[7] Yu.E. Pivinskij, T. N. Epifanova, and N. A. Peretokina, "Materials on basis of highly concentrated ceramic binding suspensions. Production and properties of fine-grained foamed concretes on basis of quartz sand suspensions," Ogneupory i Tekhnicheskaya Keramika, no. 10, pp. 5-10, 1998.

[8] K. Łaskawiec, J. Małolepszy, and G. Zapotoczna-Sytek, "Influence of fly ashes generated at burning hard and brown coal in fluidized boilers on AAC phase composition," Materialy Ceramiczne/Ceramic Materials, vol. 63, no. 1, pp. 88-92, 2011.

[9] O. A. Melville, N. A. Rice, I. Therrien, and B. H. Lessard, "Organic thin-film transistors incorporating a commercial pigment (Hostasol Red GG) as a low-cost semiconductor," Dyes and Pigments, vol. 149, pp. 449-455, 2018. 
[10] D.-H. Qiu, Q.-Y. Wen, Q.-H. Yang, Z. Chen, Y.-L. Jing, and H.-W. Zhang, "Growth of vanadium dioxide thin films on Pt metal film and the electrically-driven metal-insulator transition characteristics of them," Wuli Xuebao/Acta Physica Sinica, vol. 62, no. 21, p. 217201, 2013.

[11] Y. Ren, H. Wei, X. Huang, and J. Ding, "A facile synthesis of $\mathrm{SiO}_{2} @ \mathrm{C} @$ graphene composites as anode material for lithium ion batteries," International Journal of Electrochemical Science, vol. 9, no. 12, pp. 7784-7794, 2014.

[12] D. Bamba, M. Coulibaly, C. I. Fort et al., "Synthesis and characterization of $\mathrm{TiO}_{2} / \mathrm{C}$ nanomaterials: applications in water treatment," Physica Status Solidi (B), vol. 252, no. 11, pp. 2503-2511, 2015.

[13] T. P. Chou, Q. Zhang, G. E. Fryxell, and G. Z. Cao, "Hierarchically structured $\mathrm{ZnO}$ film for dye-sensitized solar cells with enhanced energy conversion efficiency," Advanced Materials, vol. 19, no. 18, pp. 2588-2592, 2007.

[14] P. Lv, H. Zhao, J. Wang, X. Liu, T. Zhang, and Q. Xia, "Facile preparation and electrochemical properties of amorphous $\mathrm{SiO}_{2} / \mathrm{C}$ composite as anode material for lithium ion batteries," Journal of Power Sources, vol. 237, pp. 291-294, 2013.

[15] M. A. El-Sayed, "Some interesting properties of metals confined in time and nanometer space of different shapes," Accounts of Chemical Research, vol. 34, no. 4, pp. 257-264, 2001.

[16] K. Awazu, M. Fujimaki, C. Rockstuhl et al., "A plasmonic photocatalyst consisting of silver nanoparticles embedded in titanium dioxide," Journal of the American Chemical Society, vol. 130, no. 5, pp. 1676-1680, 2008.

[17] P. K. Jain, X. Huang, I. H. El-Sayed, and M. A. El-Sayed, "Review of some interesting surface plasmon resonanceenhanced properties of noble metal nanoparticles and their applications to biosystems," Plasmonics, vol. 2, no. 3, pp. 107-118, 2007.

[18] R. Narayanan and M. A. El-Sayed, "Effect of nanocatalysis in colloidal solution on the tetrahedral and cubic nanoparticle SHAPE: electron-transfer reaction catalyzed by platinum nanoparticles," Journal of Physical Chemistry B, vol. 108, no. 18, pp. 5726-5733, 2004.

[19] X. Huang, P. K. Jain, I. H. El-Sayed, and M. A. El-Sayed, "Gold nanoparticles: interesting optical properties and recent applications in cancer diagnostics and therapy," Nanomedicine, vol. 2, no. 5, pp. 681-693, 2007.

[20] Yu.P. Mukha, A. M. Eremenko, N. P. Smirnova, A. O. Doroshenko, I. P. Terenetskaya, and T. H. Orlova, "Influence of gold nanoparticles in $\mathrm{SiO}_{2}$ matrix on the spectral properties and photochemistry of adsorbed molecules of Rhodamine 6G and provitamin D," Nanosystems, Nanomaterials, Nanotechnologies, vol. 8, no. 4, pp. 813-828, 2010.

[21] S. O. Cherkasova, A. P. Budnik, and A. A. Tsaturyan, "Structural, electronic and optical properties of $\mathrm{Cu}$-doped $\mathrm{SiO}_{2}$ glass," in Proceedingsof the International Workshop for Young Researchers @Smart Materials \&Mega-Scale Research Facilities, Rostov-on-Don, Russia, October 2018.

[22] S. Xiang, Y. Zhou, Y. Zhang et al., "A highly reactive and enhanced thermal stability nanocomposite catalyst based on $\mathrm{Au}$ nanoparticles assembled in the inner surface of $\mathrm{SiO}_{2}$ hollow nanotubes," Dalton Transactions, vol. 43, no. 28, pp. 11039-11047, 2014.

[23] A. Saini, T. Maurer, I. I. Lorenzo et al., "Synthesis and SERS application of $\mathrm{SiO}_{2} @ \mathrm{Au}$ nanoparticles," Plasmonics, vol. 10, no. 4, pp. 791-796, 2015.

[24] Q. Zhang, S. Yang, T. Zhu, J. K. Oh, and P. Li, "Softnanocoupling between silica and gold nanoparticles based on block copolymer," Reactive and Functional Polymers, vol. 110, no. 1, pp. 30-37, 2017.

[25] S. Han and B. J. Lee, "Electromagnetic resonance modes on a two-dimensional tandem grating and its application for broadband absorption in the visible spectrum," Optics Express, vol. 24, no. 2, pp. A202-A214, 2016.

[26] N. A. Matveyevskaya, V. P. Seminozhenko, N. O. MchedlovPetrosyan, A. V. Tolmachyov, and N. I. Shevtsov, "Obtaining, structure and properties of $\mathrm{SiO}_{2} / \mathrm{Au}$ heteronanoparticles," Reports of the National Academy of Sciences of Ukraine, vol. 2, pp. 101-107, 2007.

[27] B.-T. Liu, J.-R. Syu, and D.-H. Wang, "Preparation and characterization of conductive $\mathrm{SiO}_{2}$-polyaniline core-shell nanoparticles," International Journal of Chemical Engineering and Applications, vol. 4, no. 4, pp. 209-212, 2013.

[28] G. E. Remnev, E. G. Furman, A. I. Pushkarev, S. B. Karpuzov, N. A. Kondrat'ev, and D. V. Goncharov, "A high-current pulsed accelerator with a matching transformer," Instruments and Experimental Techniques, vol. 47, no. 3, pp. 394-398, 2004.

[29] A. Pushkarev, G. Kholodnaya, R. Sazonov, and D. Ponomarev, "Thermal imaging diagnostics of high-current electron beams," Review of Scientific Instruments, vol. 83, no. 10, article 103301, 2012

[30] G. Kholodnaya, D. Ponomarev, R. Sazonov, and G. Remnev, "Characteristics of pulsed plasma-chemical synthesis of silicon dioxide nanoparticles," Radiation Physics and Chemistry, vol. 103, pp. 114-118, 2014.

[31] G. Kholodnaya, R. Sazonov, D. Ponomarev, and G. Remnev, "Pulsed plasma chemical synthesis of $\mathrm{Si}_{x} \mathrm{C}_{y} \mathrm{O}_{z}$ composite nanopowder," Journal of Physics: Conference Series, vol. 830, no. 1, article 012035, 2017.

[32] G. Kholodnaya, R. Sazonov, D. Ponomarev, and T. Guzeeva, "Plasma chemical conversion of sulphur hexafluoride initiated by a pulsed electron beam," Radiation Physics and Chemistry, vol. 130, pp. 273-276, 2017.

[33] W. S. Ahn, K. K. Kang, and K. Y. Kim, "Synthesis of TS-1 by microwave heating of template-impregnated $\mathrm{SiO}_{2}-\mathrm{TiO}_{2}$ xerogels," Catalysis Letters, vol. 72, no. 3/4, pp. 229-232, 2001.

[34] T. Maruizumi, J. Ushio, and M. Miyao, "Molecular orbital theory examination into improved gate oxide integrity through the incorporation of nitrogen and fluorine," Journal of Non-Crystalline Solids, vol. 246, no. 1-2, pp. 73-82, 1999.

[35] A. O. Zamchiy, E mch Baranov, S. Y. Khmel, E. A. Maximovskiy, D. V. Gulyaev, and K. S. Zhuravlev, "Deposition time dependence of the morphology and properties of tin-catalyzed silicon oxide nanowires synthesized by the gas-jet electron beam plasma chemical vapor deposition method," Thin Solid Films, vol. 654, pp. 61-68, 2018.

[36] D. V. Ponomarev, G. E. Remnev, R. V. Sazonov, and G. E. Kholodnaya, "Pulse plasma-chemical synthesis of ultradispersed powders of titanium and silicon oxide," IEEE Transactions on Plasma Science, vol. 41, no. 10, pp. 2908-2912, 2013. 


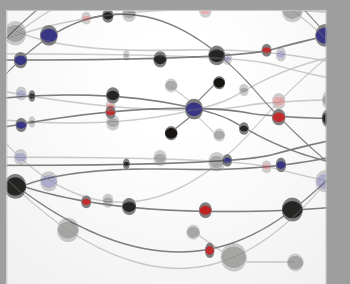

The Scientific World Journal
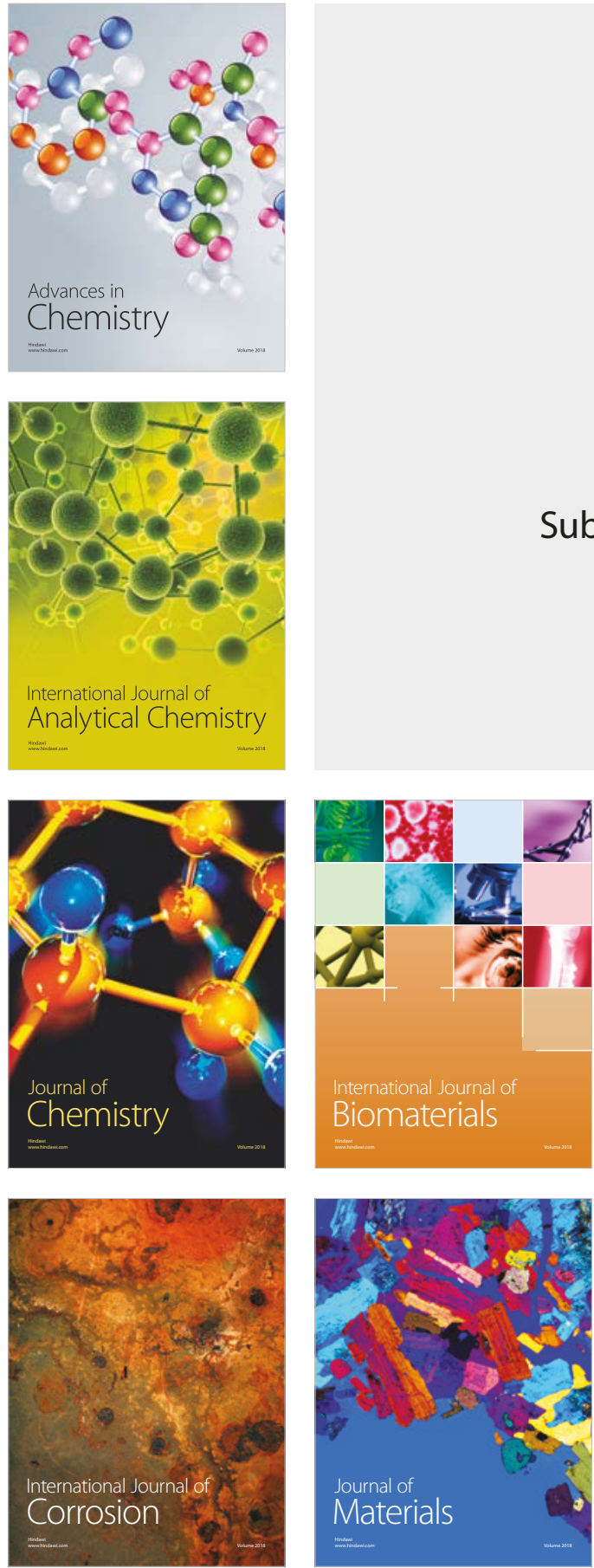

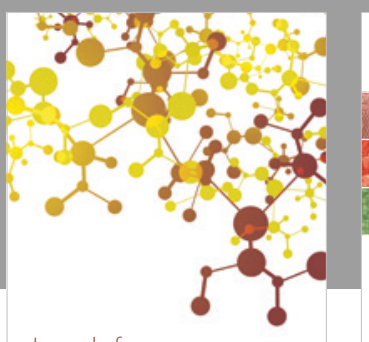

Journal of

Applied Chemistry
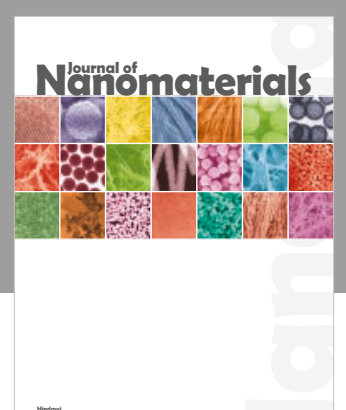

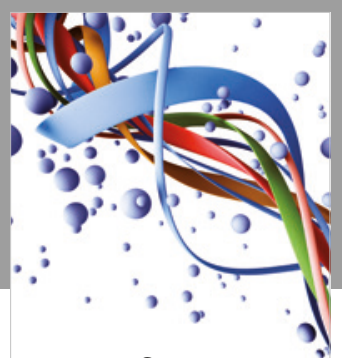

Scientifica

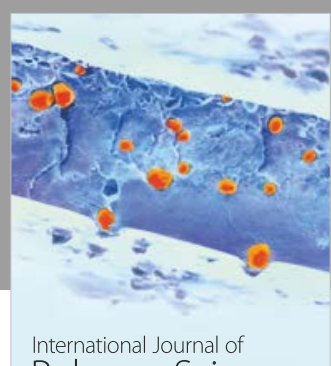

Polymer Science

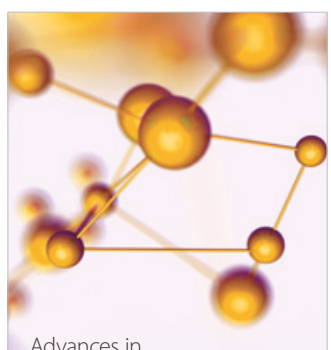

Physical Chemistry
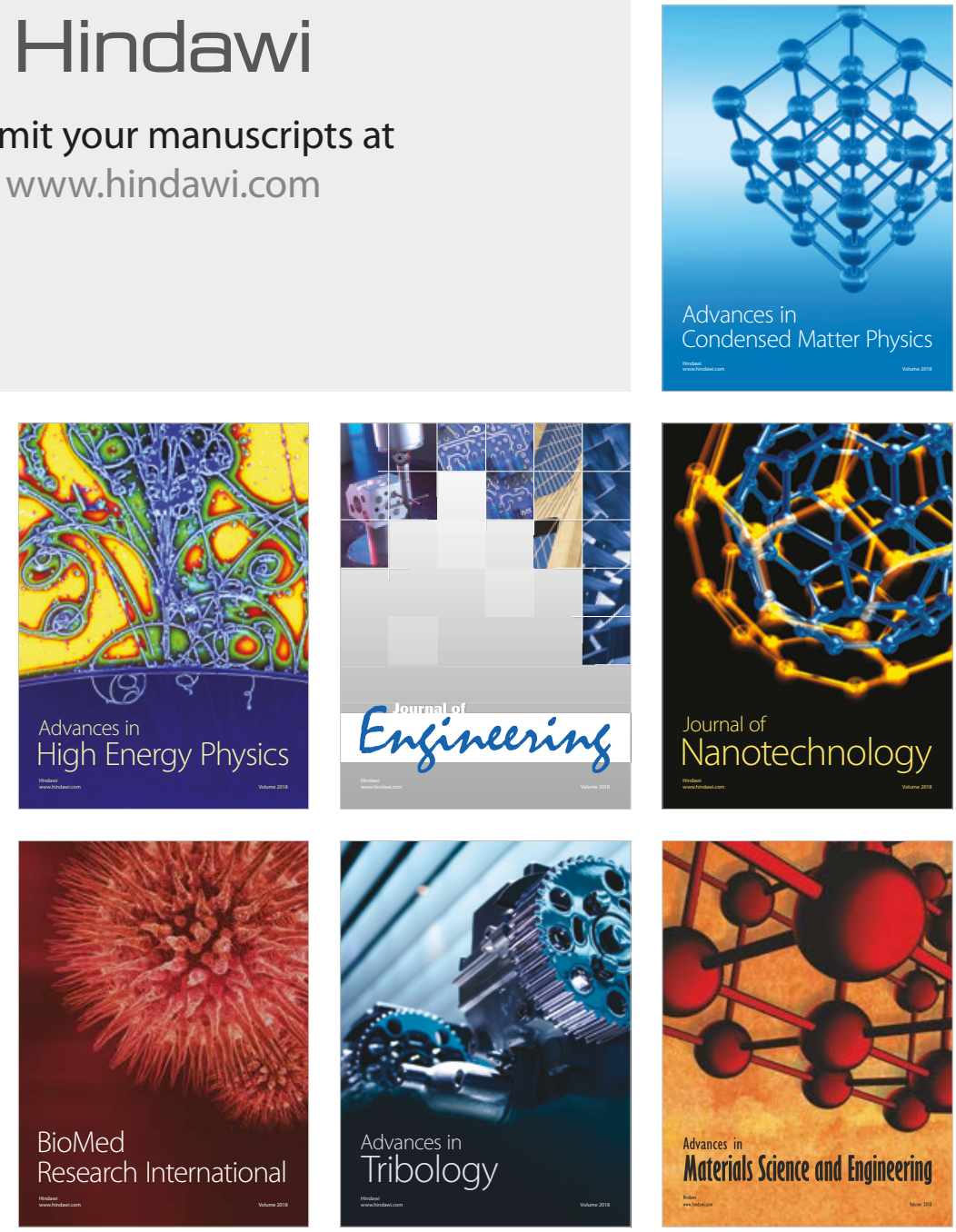